\title{
Lesión osteolítica de calota por sífilis secundaria
}

\author{
Lucas Alessandro, Julieta Pilar Camporro, Naomi Arakaki, Nora Orellana y Claudia Andrea Mora
}

\footnotetext{
Instituto de Investigaciones Neurológicas Raúl Carrea-FLENI. Buenos Aires, Argentina. Servicio de Neurología (LA) Medicina Interna (JPC), Patología (NA), Bacteriología (NA), Infectología (CAM)

Los autores no tienen conflictos de interés para declarar ni recibieron financiación para la realización de artículo.

Recibido: 23 de agosto de 2015 Aceptado: 4 de marzo de 2016

Correspondencia a: Lucas Alessandro lalessandro@fleni.org.ar
}

\section{Injury by skull osteolytic secundary syphilis}

Bone involvement of syphilis can be observed in tertiary and congenital syphilis. It is infrequent during the secondary stage. The skull is the most affected bone in secondary syphilis, and its most frequent form of presentation is proliferative osteitis. If the skull is affected, headache is usual and can be as intense as in meningitis. Osteolyitic lesions may be seen in complimentary imaging studies, with a moth eaten aspect. These lesions raise concern over a number of differential diagnoses, among which are infectious, inflammatory and neoplastic diseases. The definitive diagnosis is made by bone biopsy of the compromised bone. Molecular techniques in the affected tissues increases diagnostic performance. There is no standardized treatment protocol for syphilis since there are no guidelines available. We report a case of a 19 year old female, presenting with a unique osteolytic lesion in the skull due to secondary syphilis.

Key words: Syphilis, one, skull, osteitis, osteolytic.

Palabras clave: Sífilis, hueso, calota, osteítis, osteolítico.

\section{Introducción}

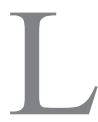
a sífilis es causada por Treponema pallidum, bacteria fina y elongada de $0,1-0,18 \mu \mathrm{m}$ por $6-20 \mu \mathrm{m}$, de la familia Espirochaetaeceae que, debido a su tamaño, no puede ser visualizada por microscopia directa. Además, no es posible su cultivo in vitro. Su transmisión se produce por el contacto directo con lesiones infecciosas a través de disrupciones del epitelio en sitios de trauma menor durante la actividad sexual ${ }^{1}$. Clínicamente, se divide en dos etapas: sífilis temprana (período de incubación, sífilis primaria, secundaria y latente temprana) y tardía (latente tardía y sífilis terciaria). Durante la fase primaria se desarrolla la primera lesión en la piel o mucosa conocida como chancro, lesión indolora que aparece en el lugar de inoculación y se resuelve espontáneamente entre dos y ocho semanas. La fase secundaria comienza entre dos y 12 semanas luego del primer contacto, en la cual se produce diseminación de los treponemas, tanto por vía linfática como hematógena, provocando manifestaciones mucocutáneas (exantemas, úlceras), constitucionales y parenquimatosas, con la potencial afección de múltiples tejidos, entre ellos el óseo (principalmente, osteítis) ${ }^{2}$. La sífilis tardía se refiere a la aparición de manifestaciones clínicas (1 a 30 años luego de la infección) que se desarrollan aproximadamente en un tercio de los pacientes no tratados. Su base patológica son las alteraciones en los vasa vasorum, presentando alteraciones cardíacas, neurológicas y lesiones características denominadas gomas, que afectan al hueso, entre otros tejidos.

El diagnóstico se realiza mediante métodos directos (microscopia de campo oscuro, tinción argéntica como la de Warthin-Starry, inmununofluorescencia o técnicas moleculares) de los tejidos afectados o mediante métodos indirectos, como la serología no treponémica (VDRL, RPR) y treponémica (FTAbs, MHA-TP) ${ }^{3}$.

El tratamiento de elección es penicilina y la formulación benzatínica intramuscular para la mayoría de los estadios, excepto para la neurosífilis y la sífilis congénita, donde se administra penicilina $\mathrm{G}$ sódica cristalina intravenosa ${ }^{4}$.

El compromiso óseo se observa predominantemente en la sífilis terciaria y sífilis congénita. Sin embargo, se han descrito casos producidos durante la sífilis secundaria ${ }^{5}$. En dichos casos, los huesos más afectados son el cráneo, esternón y tibia. La forma más frecuente de presentación es la osteítis proliferativa, manifestada por dolor (predominantemente nocturno) e inflamación de los tejidos adyacentes ${ }^{6}$. Cuando afecta la calota, la cefalea es habitual $\mathrm{y}$ puede ser tan intensa que puede confundirse con un proceso meníngeo ${ }^{7}$. En general, el curso es afebril, aunque cuanto más destructiva sea la afectación, mayores son los síntomas constitucionales ${ }^{8}$. El compromiso óseo puede preceder o seguir a las manifestaciones mucocutáneas y, en algunos casos, puede ocurrir como única manifestación?.

Se presenta el caso de una mujer de 19 años con una lesión en calota osteolítica única debida a sífilis secundaria.

\section{Caso clínico}

Mujer de 19 años de edad, con antecedentes de angioma congénito en un muslo y convulsiones febriles 
durante la infancia. Consultó por un cuadro de cefalea frontal izquierda opresiva acompañado de un escotoma centellante del ojo izquierdo, con un mes y medio de evolución. Dos días previos a la consulta se agregó un aumento de volumen frontal izquierdo. Al examen físico de su ingreso, se constató una temperatura axilar de $37,5^{\circ} \mathrm{C}$, una tumefacción en la región frontal izquierda, dolorosa a la palpación, inmóvil y con un leve eritema de la piel supradyacente. En la boca presentaba una lesión tipo afta en el borde lateral de la lengua y una úlcera en el paladar blando, de bordes irregulares, de color rosáceo-pálido, indolora, que le generaba odinofagia. El resto de examen físico, incluido el articular y neurológico era normal. En el laboratorio, como hallazgos de relevancia, se obtuvo una velocidad de eritrosedimentación de $20 \mathrm{~mm} / \mathrm{h}$ (valor normal: $0-20 \mathrm{~mm} / \mathrm{h}$ ) y una PCR de $8,86 \mathrm{mg} / \mathrm{L}$ (valor normal: $0-5 \mathrm{mg} / \mathrm{L})$. La serología para VIH resultó negativa. La radiografía de tórax fue normal y la prueba de tuberculina (PPD) fue negativa. Se realizó una tomografía axial computarizada (TAC) de cerebro sin contraste que mostró una lesión osteolítica de aspecto apolillado que comprometía la tabla interna, diploe y tabla externa en el hueso frontal izquierdo (Figura 1). En la resonancia magnética $(\mathrm{RM})$ de cerebro se evidenció una captación heterogénea de contraste, asociado a un refuerzo paquimeníngeo con engrosamiento de los tejidos blandos, de localización subgaleal, adyacentes a la lesión (Figura 2). Se realizó una punción lumbar, obteniéndose un LCR claro, sin células, con glucorraquia y proteinorraquia normal; la tinción directa y los cultivos para bacterias, micobacterias y hongos fueron negativos. Se tomaron cultivos del borde y centro de la úlcera oral para bacterias comunes, micobacterias, hongos, Actinomyces, Nocardia y búsqueda para antígenos de herpes simplex 1 y 2; todos resultaron negativos. No se realizó biopsia de la lesión oral. En virtud a los resultados microbiológicos preliminares negativos, y a que la paciente evolucionó con mayor cefalea, se realizó una biopsia del hueso y porción de la meninge afectada. El análisis histopatológico mostró un infiltrado linfoplasmocitario, sin evidencia de células multinucleadas, granulomas ni atipias, presencia de tractos fibrosos y ausencia de microorganismos en las tinciones de Ziehl-Neelsen, Whartin-Starry y PAS. Se realizaron inmunomarcaciones para ALK y desmina con resultados
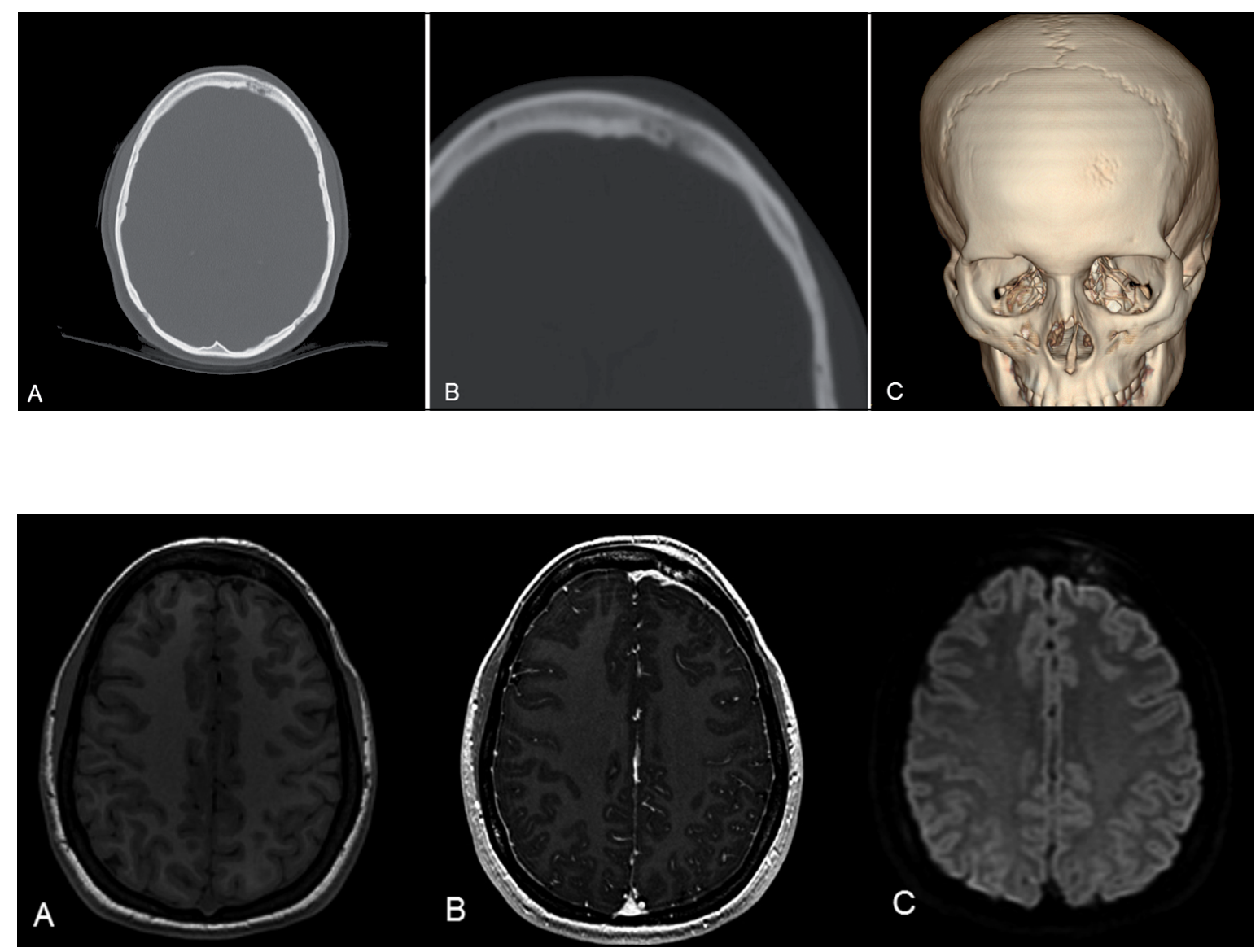

Figura 2. RM de cerebro. T1 (A); T1 con contraste (B) y difusión (C). Captación heterogénea de contraste, asociada a refuerzo paquimeníngeo y engrosamiento de tejidos blandos en localización subgaleal adyacente, con restricción difusa a nivel óseo. 

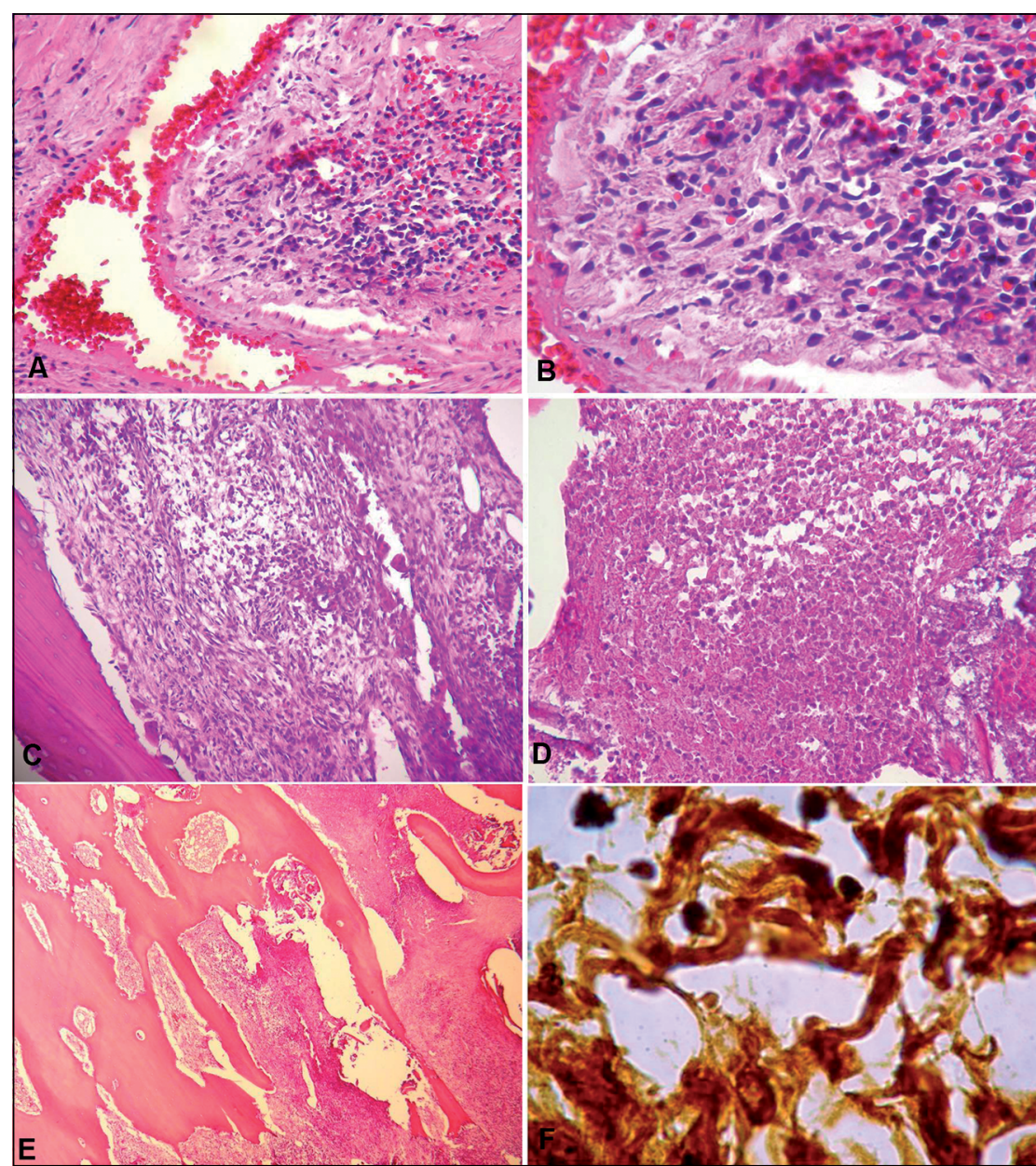

Figura 3. Anatomía patológica. Hematoxilina-eosina de meninge (A-B); calota (C-D-E) y WhartinStarry (E). Infiltrado linfoplasmocitario sin atipias conjunto a tractos fibrosos, en tinción de WhartinStarry no se observan microorganismos. negativos, descartando un pseudotumor inflamatorio (Figura 3). Reinterrogando a la paciente, ésta recordó un cuadro de una erupción papular en codos y rodillas, asociado a una inflamación articular con faringitis tres meses previos a la consulta, que había sido interpretado como estreptocócico, por lo que había recibido una dosis de penicilina benzatina intramuscular. Por dicho motivo, se realizó un VDRL y FTAbs en suero y LCR, siendo ambos test positivos en suero (VDRL 1:64) y negativos en LCR. Se completó el estudio histopatológico con una reacción de polimerasa en cadena (RPC) para T. pallidum del material óseo de la biopsia, que resultó positivo.

Debido al tiempo transcurrido entre las primeras manifestaciones clínicas y el compromiso óseo, a la lesión mucosa concomitante característica del secundarismo sifilítico y a los hallazgos histopatológicos (ausencia de gomas), se interpretó el cuadro como una sífilis secundaria con compromiso óseo. Debido a que la paciente presentaba un realce meníngeo adyacente a la lesión ósea, a pesar que el LCR no fue inflamatorio con VDRL negativo, y ante la imposibilidad de descartar un compromiso del SNC por contigüidad, se decidió realizar terapia combinada con dos dosis de penicilina benzatina intramuscular (con intervalo de una semana) y penicilina $\mathrm{G}$ sódica cristalina intravenosa durante 14 días. La paciente tuvo una buena respuesta clínica (mejoría inmediata tras la finalización del tratamiento), desaparición de los hallazgos imagenológicos y niveles en descenso de VDRL plasmático a los seis meses (1:4). Dada la respuesta favorable tras el tratamiento antimicrobiano, se decidió no avanzar con otras medidas terapéuticas.

\section{Discusión}

El compromiso óseo en la sífilis secundaria es un hallazgo infrecuente, existiendo sólo series y comunicaciones de casos $^{8,10,11}$. Sin embargo, en los últimos años, éstos han ido aumentando debido a la co-infección con $\mathrm{VIH}^{12,13}$. A pesar de su infrecuencia, su diagnóstico es importante ya que puede ocasionar la destrucción y deformidad del hueso, provocando desde trastornos funcionales hasta la muerte secundario a la sepsis ${ }^{14}$.

Los huesos más comúnmente afectados son los huesos largos de las extremidades, cráneo y costillas ${ }^{15}$. El compromiso craneal se da principalmente en el hueso frontal, parietal y naso-palatino ${ }^{16}$. Las lesiones destructivas de calota se presentan como áreas irregulares, donde la tabla externa es la más frecuentemente afectada, pudiendo también comprometerse los tejidos blandos circundantes ${ }^{17}$. El compromiso óseo plantea el diagnóstico diferencial con otras patologías infecciosas, inflamatorias y neoplásicas, desde benignas a graves. En niños y adolescentes los diagnósticos diferenciales son los hemangiomas, la histiocitosis $\mathrm{X}$, la displasia fibrosa y el sarcoma de Ewing, mientras que en adultos debe distinguirse de la enfermedad de Paget, el mieloma múltiple y las metástasis, predominantemente de pulmón, mama, riñón y tiroides, entre otros ${ }^{14}$.

El diagnóstico de sífilis secundaria se realiza por los signos clínicos (las lesiones cutáneas polimorfas predominantemente palmo-plantares y las poliadenopatías constituyen la clave diagnóstica) ${ }^{18} \mathrm{y}$ mediante las pruebas serológicas. Durante este estadio, la sensibilidad del VDRL es de $100 \%$ con una especificidad entre 85 $99 \%$; esta última puede estar reducida en pacientes con co-morbilidades (enfermedades reumatológicas) y en el embarazo. En la sífilis secundaria el FTAbs presenta una sensibilidad cercana a $100 \%$ con una especificidad de $96 \%{ }^{19}$. El compromiso óseo se confirma con la biopsia y el análisis histopatológico del hueso afectado, demostrando 
un infiltrado linfoplasmocitario perivascular, con tejido de granulación y necrosis, a diferencia de lo observado en los gomas sifilíticos en los cuales se visualizan granulomas ${ }^{20}$. Las tinciones que permiten visualizar al T. pallidum en los tejidos son las técnicas de impregnación argéntica como Warthin-Starry y la de inmunofluorescencia, aunque el rendimiento de las mismas en hueso es desconocido. El método de mayor sensibilidad y especificidad en los tejidos analizados es la RPC, con 76,8-100\% y 95,4-100\%, respectivamente ${ }^{4}$. Dichas pruebas se basan principalmente en la detección de dos genes: $t p N 47$ (que codifica una proteína de membrana de $47 \mathrm{kDa}$ ) y polA (que codifica para la ADN polimerasa I $)^{21}$. Sin embargo, hasta el momento existe sólo una comunicación de un caso donde se realizó RPC a una muestra ósea ${ }^{22}$. En nuestro caso, la técnica utilizada disponible en el centro de referencia para enfermedades infecciosas de nuestro país, fue el polA.

El tratamiento del compromiso óseo producido durante la sífilis secundaria es discutido, debido a que no existen revisiones ni guías que permitan establecer estrategias terapéuticas claras. En algunos reportes de casos, los pacientes fueron tratados siguiendo la conducta habitual para la sífilis secundaria, es decir, penicilina benzatina intramuscular ${ }^{14,15,23}$, mientras que en otros, el tratamiento elegido fue penicilina $\mathrm{G}$ sódica cristalina intravenosa. Debido a que nuestra paciente presentaba compromiso meníngeo por imágenes (hasta $4 \%$ de los pacientes con neurosífilis pueden tener LCR normal) ${ }^{20}$ y a que había recibido tratamiento previo con penicilina benzatina (que podría haber atenuado los hallazgos clínicos, de laboratorio y de imágenes evidenciados), se decidió tratar con penicilina $\mathrm{G}$ sódica cristalina intravenosa. Si bien el compromiso óseo habitualmente en la sífilis secundaria es una osteítis proliferativa ${ }^{6}$, la cual se beneficiaría de los esquemas habituales con penicilina benzatina, creemos, al igual que otros reportes ${ }^{25}$, que la terapia en lesiones de tipo osteolítico podría prolongarse. Incluso después de realizar el tratamiento del secundarismo, se podría evaluar mantener al paciente con tetraciclinas por tiempo más prolongado si la lesión ósea no mejora rápidamente. Sin embargo, a diferencia de lo que ocurre en la osteomielitis por microorganismos habituales, la respuesta a la terapia en nuestro caso fue de forma inmediata, por lo que creemos que son entidades que no pueden homologarse estrictamente.

Agradecimientos: A Patricia Galarza, Servicio de ETS de I.N.E-A.N.L.I.S, Carlos G. Malbran, Ismael L. Calandri, Servicio de Neurología. FLENI y a Joaquín Mercado, Servicio de Medicina Interna. FLENI.

\section{Resumen}

El compromiso óseo de la sífilis se observa predominantemente en la sífilis terciaria y en la sífilis congénita, siendo infrecuente durante el estadio secundario. El hueso más afectado durante la sífilis secundaria es el cráneo, siendo la osteítis proliferativa la forma más frecuente de presentación. Cuando afecta la calota, la cefalea es habitual y puede ser tan intensa que se confunde con un proceso meníngeo. En las imágenes se observan lesiones líticas de aspecto apolillado, planteando el diagnóstico diferencial con otras patologías infecciosas, inflamatorias y neoplásicas. El diagnóstico definitivo se realiza por estudio histológico del hueso comprometido. Las técnicas de biología molecular en los tejidos afectados aumentan el rendimiento diagnóstico. No existen protocolos estandarizados para el tratamiento de la sífilis con compromiso óseo. Presentamos el caso clínico de una mujer de 19 años de edad, con una lesión osteolítica única de calota debida a una sífilis secundaria.

\section{Referencias bibliográficas}

1.- Hook E W 3 $3^{\text {rd }}$, Marra C M. Acquired syphilis in adults. N Engl J Med 1992; 326: 1060-9.

2.- Micihaan M G, Contarelli J N. Capítulo 31: Infecciones de transmisión sexual. En Cecchini E, González Ayala S. Infectología y Enfermedades Infecciosas, $1^{\text {era }}$ ed. Ediciones Journal, 2007: 209-29.

3.- Tipple C, Taylor G P. Syphilis testing, typing, and treatment follow-up: a new era for an old disease. Curr Opin Infect Dis 2015; 28: 53-60.

4.- Clement M E, Okeke N L, Hicks C B. Treatment of syphilis: a systematic review. JAMA 2014; 312: 1905-17.

5.- Thompson R G, Preston R H. Lesions of the skull in secondary syphilis. Am J Syph Gonorrhea Vener Dis 1952; 36: 332-41.

6.- Gurland I A, Korn L, Edelman L, Wallach F. An unusual manifestation of acquired syphilis. Clin Infect Dis 2001; 32: 667-9.

7.- Davidson F, Bruckner F E. Bone invasion in secondary syphilis. Genitourin Med 1989; 65: 60.

8.- Reynolds F, Wasserman H. Destructive osseous lesions in early syphilis. Arch Intern Med (Chic.) 1942; 69: 263-76.

9.- Middleton S, Rowntree C, Rudge S. Bone pain as the presenting manifestation of secondary syphilis. Ann Rheum Dis 1990; 49: 641-2.

10.- Waugh M A. Bony symptoms in secondary syphilis. Br J Vener Dis 1976; 52: 204-5.

11.- Mindel A, Tovey S J, Timmins D J,
Williams P. Primary and secondary syphilis, 20 years' experience. 2. Clinical features. Genitourin Med 1989; 65:1-3.

12.- Elopre L, Morell V, Bosshardt C, Geisler W M. A case of syphilitic osteitis in a patient with HIV infection. Int J STD AIDS 2014; 25: 765-7.

13.- Boix V, Merino E, Reus S, Torrus D, Portilla J. Polyostotic osteitis in secondary syphilis in an HIV-infected patient. Sex Transm Dis 2013; 40: 645-6.

14.- Dismukes W E, Delgado D G, Mallernee S V, Myers T C. Destructive bone disease in early syphilis. JAMA 1976; 236: 2646-8.

15.- Park K H, Lee M S, Hong I K, Sung J Y, Choi S H, Park S O, et al. Bone involvement in secondary syphilis: a case report and systematic 
review of the literature. Sex Transm Dis 2014; 41: 532-7.

16.- Bauer M F, Caravati C M Jr. Osteolytic lesions in early syphilis. Br J Vener Dis 1967; 43: 175-7.

17.- Ehrlich R, Kricun M E. Radiographic findings in early acquired syphilis: case report and critical review. Am J Roentgenol 1976; 127: 789-92.

18.- Thompson R G, Preston R H. Lesions of the skull in secondary syphilis. Am J Syph Gonorrhea Vener Dis 1952; 36: 332-41.

19.- Workowski K A, Levine W C. Selected topics from the Centers for Disease Control and Prevention sexually transmitted diseases treatment guidelines 2002. HIV Clin Trials 2002; 3: 421-33.

20.- Tramont E C. Treponema pallidum (Syphilis). Mandell G L, Bennett J E, Dolin R, eds. Principles and Practice of Infectious Diseases. Churchill Livingstone, Philadephia, $7^{\text {th }}$ edition, 2009: 2768-83.

21.- García P, Grassi B, Fich F, Salvo A, Araya L, Abarzúa F, et al. Diagnóstico de la infección por Treponema pallidum en pacientes con sífilis temprana y neurosífilis mediante reacción de la polimerasa en cadena. Rev Chilena Infectol 2011; 28: 310-5.

22.- Kandelaki G, Kapila R, Fernandes H. Destructive osteomyelitis associated with early secondary syphilis in an HIV-positive patient diagnosed by Treponema pallidum DNA polymerase chain reaction. AIDS Patient Care STDS 2007; 21: 229-33.

23.- Strada M, Gariboldi M, Segalini G, Meregaglia D. Secondary syphilis. Localizations in the bones of the skull. Radiol Med 1987; 73: 453-4.

24.- Workowski K A, Bolan G A. Sexually transmitted diseases treatment guidelines. Reprod Endocrinol 2015; 24: 51-6.

25.- Egan K M, Walters M C. Osseous and meningeal involvement in secondary syphilis. Dermatol Online J 2012; 18:1. 